\title{
Vein structures, like ripple marks, are formed by
}

\author{
short-wavelength shear waves
}

\author{
Tsuneo Ohsumi a, Yujiro Ogawa ${ }^{\text {b, * }}$ \\ ${ }^{a}$ Nippon Koei Co Ltd. R\&D Center, 2304 Inarihara, Tsukuba, Ibaraki 300-1259, Japan \\ (E-mail:a3850@n-koei.co.jp) \\ ${ }^{b}$ Doctoral Program in Earth Evolution Sciences, University of Tsukuba, Tsukuba, Ibaraki \\ 305-8572, Japan (E-mail: fyogawa45@yahoo.co.jp) \\ Accepted 5 February, 2008
}

\begin{abstract}
Vein structure, a distinctive structure in deep-sea hemipelagic clayey and siliceous mudstones at convergent plate boundaries, consists of closely spaced mud-filled veins forming an array usually parallel to the bedding plane. This structure has been regarded as a seismite that formed during earthquake shaking by resonance of fractures. Our detailed field observations and shaking model experiments verified that both basic (first-stage) and advanced (developed-stage) vein structures can be explained by a systematic theory. Essentially, a vein structure forms in an array of fractures as a result of shearing, not by push waves but by shear waves of very short wavelength, by a mechanism very similar to that which forms ripple marks. We found the height of a vein array $(\mathrm{H})$ to be systematically related to vein spacing $(\mathrm{S})$ such that $\mathrm{H}=5 \mathrm{~S}$, suggesting that the shear strength of the sediment is proportional to the thickness of the standing wave part of a sediment layer. Shear or oscillatory flow occurs in the top part of a sediment layer, under which standing waves with wavelengths on the order of millimeters to centimeters lead to vein structure formation. Vein structure can develop not only in response to earthquake shaking but also by propagation of shear waves along a large fault or by other kinds of shears associated with density or debris flows, landsliding, or faulting.
\end{abstract}

Keywords: Vein structure; Resonance; High frequency; Standing shear wave; Density flow; Ripple mark

* Corresponding author. Tel.: +8129853 4307, fax: +81298537887.

E-mail address: fyogawa45@yahoo.co.jp (Yujiro Ogawa)

\section{Introduction}

Vein structure was first reported on land from outcrops of Neogene deep-sea, clayey, siliceous (mostly diatomaceous) hemipelagic sedimentary rocks on the Miura and Boso peninsulas, central Japan (Ogawa, 1980; Hanamura and Ogawa, 1993). Similar structures have been recognized in DSDP-ODP cores, mostly from trench slopes, for example, from the Mid-America trench off Guatemala (Cowan, 1982; Ogawa and Miyata, 1985; Helm and Vollbrecht, 1985), the Japan trench (Arthur et al., 1980; Leggett et al., 1987; Knipe, 1986), the Izu-Bonin trench (Ogawa et al., 1992), and the Chile trench (Kemp and Lindsley-Griffin, 1990; Kemp, 1990; Lindsley-Griffin et al., 1990), as well as in many on-land examples from the Monterey and Santa Cruz formations,
California (Brothers et al., 1996).

The major characteristics of vein structure have been well described by Brothers et al. (1996). The veins of a vein structure are regularly spaced, forming an array subparallel to the bedding plane, and filled with fine, dark materials (dominantly clay or mica minerals) (Fig. 1). The veins themselves may be straight and vertical, or sigmoidal to varying degrees and either S- or Z-shaped (Figs. 1 and 2). Vein structures develop in sediments of limited age and lithology, and with a limited distribution, implying that their formation is controlled by specific conditions.

In an experimental study, Brothers et al. (1996) attributed the origin of vein structures to strain waves propagating between an upper liquefied sediment part and a relatively strong lower sediment part in which standing pressure waves form systematic fractures (veins) 


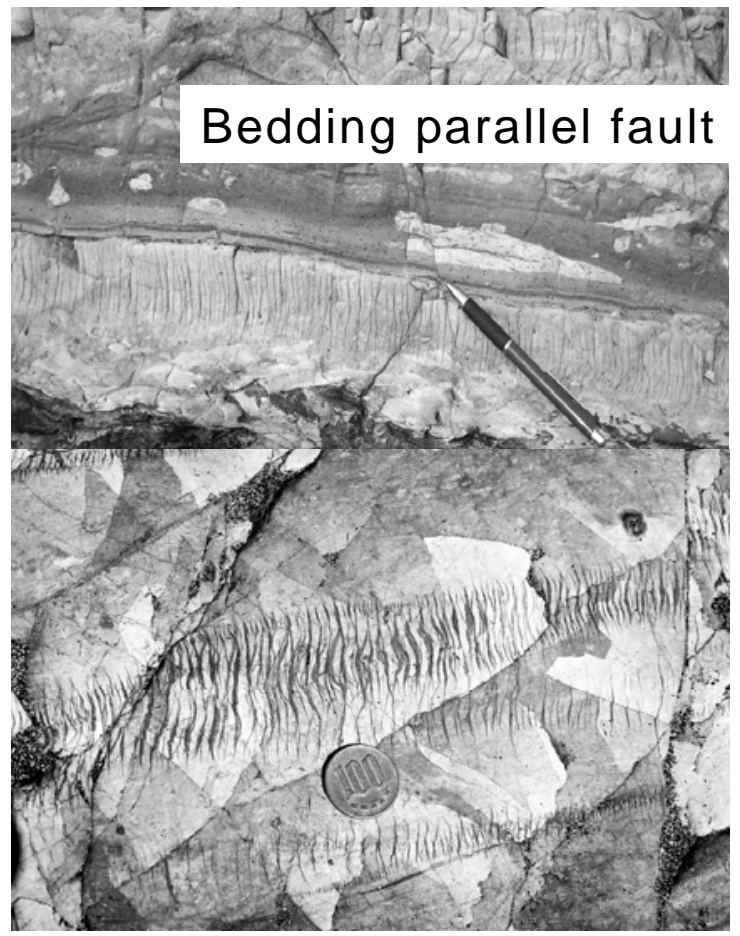

Fig. 1. Typical vein structures in upper Miocene diatomaceous mudstone, Boso Peninsula, Japan. a) Example from Nishikawana, showing a vein array formed below a bedding-parallel fault. b) Example from Motoda, showing high, bold veins with a sigmoidal shape, in between which some shorter, thinner veins are developed. Coin is $22 \mathrm{~mm}$ in diameter.

alternating with ghost veins during seismic wave shaking (vibration). Brothers et al. (1996) considered the responsible waves to be a combination of shear and pressure waves, but they did not explain the critical relationship between vein shape and arrangement regularities nor its cause. In this study, on the basis of field observations and experimental results, we explain the origin of the arrangement regularities by shearing in a liquefied sediment layer above the standing wave layer in which the vein structure forms.

We found three regularities during our critical observations in the field in the Boso Peninsula. First, the regular spacing order within a single array reflects mechanical resonance. Second, the constant ratio between array height and vein spacing further shows what factor reacts to what factor in resonance. Third, is the shape of the veins and their arrangement reflects Riedel shearing. These three regularities must be explained to resolve the true mechanism of vein structure formation.

The theory of direct origin by seismic waves cannot easily account for the wave type that is responsible for the fractures, namely one with a very short period on the order of millimeters to centimeters. Snell's law for seismic wave transmission explains that earthquake body waves approach the surface in an almost vertical direction as $\mathrm{P}$-waves and S-waves. Horizontal transmission along the earth's surface occurs by surface waves such as Love and Rayleigh waves. During a large earthquake lasting tens of seconds to some minutes, the land surface close to the hypocenter shakes strongly, with a dominant frequency of approximately 0.5 to $2 \mathrm{~Hz}$.

Earthquake waves have a wavelength some kilometers long, which is too long to be responsible for the millimeter to centimeter vein spacing. Therefore, such earthquake waves cannot directly cause vein structure formation. Another theory is needed to explain the various modes of the regular occurrence of vein structures, including the regular spacing and array height-vein spacing relationship.

Moreover, vein structures
sometimes exhibit an X-shaped arrangement where two vein arrays intersect, one with $\mathrm{S}$-shaped veins and the other with $Z$-shaped veins. These are commonly associated with bedding-parallel faults. We discuss the geological implications of this vein structure arrangement later.

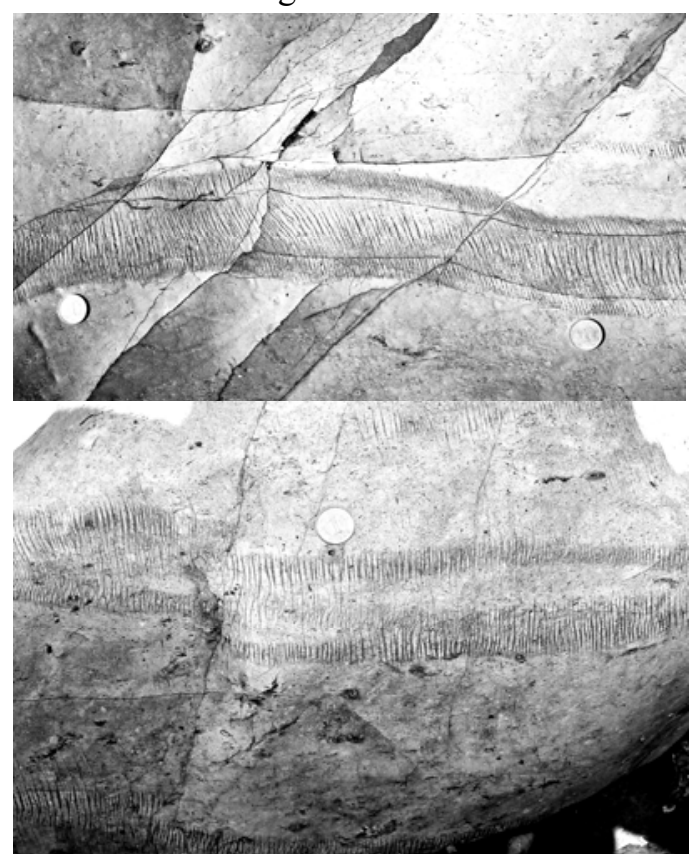

Fig. 2. Typical vein structures at Shimatogura, Boso Peninsula, showing good examples of resonance. a) The spacing ratios of the veins are $1: 1 / 2: 1 / 3$ from wide to narrow veins. b) The spacing ratios of the veins are $1: 1 / 2: 1 / 3: 1 / 4$. Coin is $20 \mathrm{~mm}$ in diameter.

\section{Vein shape and spacing and the array height-vein spacing relationship}




\subsection{Resonance}

The spacing of the veins of a vein structure is very systematic. Spaces between veins are usually one to several millimeters wide and up to several centimeters long, and the spacing is extremely regular within a particular array (Figs. 1 and 2). Within a single array, there may be several vein types of different heights (long or short) and width (bold or thin) and with different forms. We recorded the spacing of veins by measuring how many veins of each specific type occurred within a $10-\mathrm{cm}$ array length on photographs taken at outcrops with a vertically exposed plane at right angles to the strike of the vein surface.

We found a fractal relationship within the spacing ratio for vein types (ordered from long to short), that is, $1: 1 / 2: 1 / 4: 1 / 8$, etc. (normalized as 1 is the width of the longest vein with the widest spacing). In addition, we recognized an order including odd numbers in some cases: $1: 1 / 2: 1 / 3: 1 / 4: 1 / 5$, etc. (Fig. 2).

The relationship $1: 1 / 2: 1 / 4$, etc. was reported previously by Brothers et al. (1996), who also recognized the resonance. However, they did not explain the origin of such short spacing. In addition, with regard to the resonance, what is its mechanical cause? What kind of wave causes vein structure to form?

\subsection{Array height-vein spacing relationship}

Brothers et al. (1996) plotted array height and vein spacing in exposures of the Monterey Formation in California and in ocean cores drilled off Chile. They reported no systematic relationship between array height and vein spacing, perhaps because they could record only the apparent spacing, because the measured surfaces were not always at right angles to the strike of the vein surface.

We plotted the height of the vein array $(\mathrm{H})$ against the vein spacing $(\mathrm{S})$ of the basic, main (Figs. 1 and 2). We found, both for vein height shorter than $1 \mathrm{~cm}$ as well as for longer ones (several to tens of centimeters at maximum), a systematic relationship of $\mathrm{H}=5 \mathrm{~S}$ (Fig. 3), where $\mathrm{H}$ is the height of the array and $\mathrm{S}$ is the vein spacing within the array, although in some examples, the fit was better with multipliers larger than 5. It is clear, however, that at minimum, the height of a vein array is five times the vein spacing.

As already noted by Ogawa and Miyata (1985), Hanamura and Ogawa (1993) and Brothers et al. (1996), each vein in a vein structure is a fracture filled with fine, clayey particles. In addition to the relationship between the height of the vein array and vein spacing, the thickness of the individual veins may be related to the sediment strength, because the degree of fracturing depends on sediment strength.

The millimeter spacing of veins may represent half wavelengths related to certain properties of the sediment. However, as noted in the Introduction, the wavelengths of normally transmitted seismic waves are too long to explain the vein spacing. Thus, we now have to consider how the close spacing occurs.

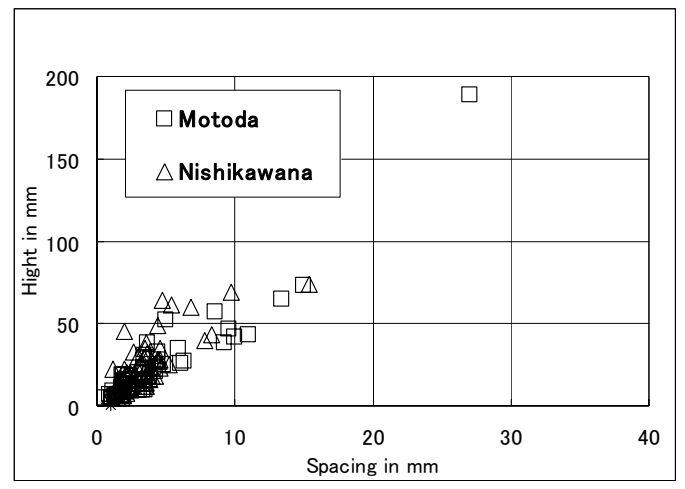

Fig. 3. Diagram showing the relation between vein spacing $(\mathrm{S}, \mathrm{mm})$ and array height $(\mathrm{H}, \mathrm{mm})$ of vein structures from two representative locations, Motoda and Nishikawana, Boso Peninsula. The lower limit suggests the strictly linear relation $\mathrm{H}=5 \mathrm{~S}$.

\section{Box experiment results and origin of the close vein spacing}

\subsection{Shearing below Density Flow}

The phenomena observed during experimental shaking of powder, as described by Brothers et al. (1996), who expanded on a suggestion made originally by Hanamura and Ogawa (1993), are as follows. When a box filled with dry clay powder $(10 \mu \mathrm{m}$ in average grain size) is shaken horizontally, the surface layer of powder in the box behaves differently from the main part below. It undergoes liquefaction, which enables the surface layer to flow. Even before oscillatory shaking begins, a system of periodic fractures similar to a vein structure always forms in the main part below the surface layer soon after the box is tilted. During 
continuous oscillatory shaking with horizontal dislocation of several to ten $\mathrm{cm}$, each cycle being one second or so, or with much faster or longer period, density flow occurs in the top several centimeters of the powder, and a standing wave forms in the denser layer below the surface layer, leading to vein structure formation (Fig. 4). Even in wet mud, a vein structure forms, although it is less visible from outside. We first explain the simplest case at the beginning of shaking, and then the more developed case, which occurs at a later stage.

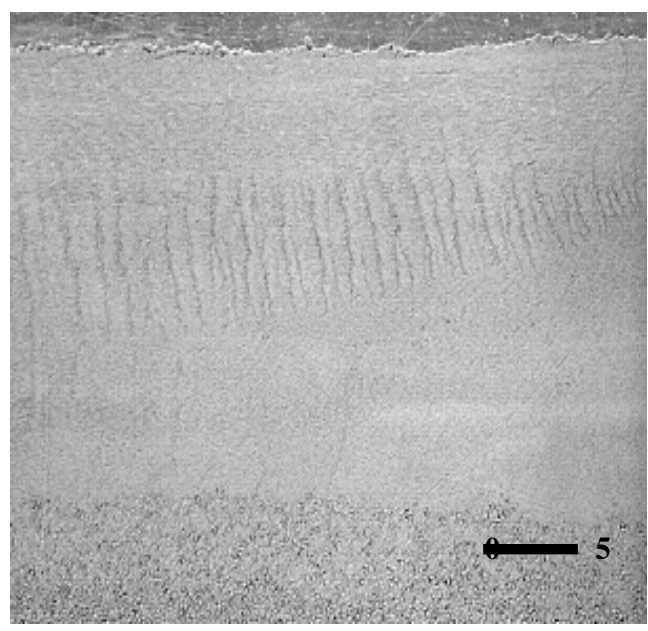

Fig. 4. Simple shaking experiment in which a basic type of vein structure formed in dry clay powder. The clear fractures (wider) are the original vein structure, and the short, slightly vague streaks are so-called ghost veins. The experiment was conducted under various conditions with the same general result. In this case, the duration was $60 \mathrm{~s}$, the shaking frequency $1.4 \mathrm{~Hz}$, and the oscillation amplitude 130 mm. Courtesy of Dr. D.E.Md.K. Hamed.

As the box is shaken, the powder separates into two parts. The upper part behaves as if liquefied, whereas the lower part remains solid and both a standing wave and fractures form. Density and strength differ in the two parts, leading to density flow and shearing. The density flow with shear causes friction between the upper and lower parts, so that a shear wave occurs along the boundary, and fractures form in the lower part by action of this shear force.

We performed various trials of a push wave experiment in which high-frequency shaking was achieved by a motor, and in no case did vein structures form. Therefore, push waves probably cannot directly cause a vein structure to form.

These observations suggest that shaking is a possible cause of vein structure formation, but a push wave is not.
In general, density flow with shearing is a plausible cause, because it can generate short shear waves along and below the flow boundary, which create fractures and veins. Further, this mechanism can also explain later modification of the vein structure by Riedel shearing. This series of processes is illustrated in Fig. 5 for the simplest case of top-to-the-right shaking of the box.

With oscillatory shaking, reciprocal displacement can occur along the boundary, causing first oscillatory shearing, then, finally, Riedel shearing creates a conjugate set of vein structure arrays, one with the top shear to the right, and the other with the top shear to the left. A natural example of a similar case is described later.

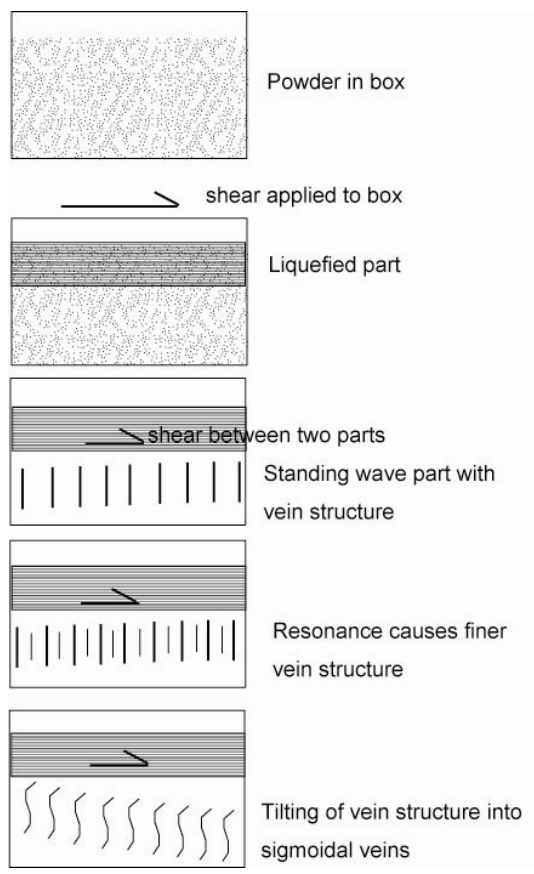

Fig. 5. Schematic diagrams showing the development of a vein structure in a shear box test. For simplicity, only the simplest example of a single shear above and to the right is illustrated. The darker top zone is the liquefied part, below which shearing occurs. Vein structures formed first as systematic fractures, then they were developed by resonance into several orders with closer spacing. Finally, veins developed in a Riedel shear zone causing the array to tilt to the right and the veins to become sigmoidal in shape.

\subsection{Mechanism of Short Spacing: Similarity to Ripple Mark}

As noted above, a shear wave occurred below the density flow, and we propose here that the features of our model are analogous to the formation of 
ripple marks in stream sediments. Sedimentological studies and textbooks (Bagnold, 1946; Yalin, 1972; Inokuchi, 1975) have reported that ripple marks display a systematic relation between wavelength $(\lambda)$ and the grain size (d) of the sediment, as follows:

$$
\lambda=1000 \mathrm{~d} \text {, }
$$

independent of other factors.

This observation may help us explain the formation of systematic vein structures. A ripple is a small topographic shape on the top surface of sediment underlying a flow (either a unidirectional current or oscillatory flow). The wavelength of a ripple is independent of the current velocity or the wave frequency; it depends only on the grain size, as mentioned above. If we assume that the grain size of the sediment below the flow is approximately $0.01 \mathrm{~mm} \mathrm{(10}$ $\mu \mathrm{m})$, then $\lambda$ is $10 \mathrm{~mm}$, which is close to double the spacing of the common, basic vein structure. In fact, in both our experiments and field observations, the grain size was around this range.

During continuous shaking lasting at least $10 \mathrm{~s}$, the veins of a vein structure became differentiated into two kinds: a fracture and a "ghost" vein, which is composed of finer materials. Brothers et al. (1996) considered the ghost veins to form at the nodes of standing waves, where finer materials became concentrated. During resonance, subsequent fractures might occur at the sites of the ghost veins, obliterating the ghost veins as a result. The spacing ratios of $1: 1 / 2: 1 / 3: 1 / 4$, etc. can be explained by resonance of fractures in natural numbers with the half-wave length $(\lambda / 2)$ as the basic spacing for the antinode.

During development, the vein fractures would become oblique to the vertical, because of dislocation by the shear stress component along an oblique plane, and then further rotated into a sigmoidal shape (Fig. 5, lowermost panel). The veins would become the seeming antithetic Riedel shears (R'), but they are not primary. In each case, the constant spacing and the periodic arrangement of both veins and ripples are important. These features can be explained by the basic spacing of the veins being proportional to the sediment grain size, which affects the strength of the specific part.

Any natural phenomenon that can cause a density flow, including landslides, debris flows, and faulting, can provide the external force to form vein structures. All are associated with high-frequency shear waves, which are needed for the formation of the regularly spaced fractures observed in vein structures. Density flows caused by landslides have a much shorter wavelength than earthquake vibrations; these waves have a frequency of 80 or higher (Ohsumi et al., 2006). In an accretionary prism, much large-scale shearing occurs in association with faulting. In such circumstances, vein structures might develop over a wide area within the prism.

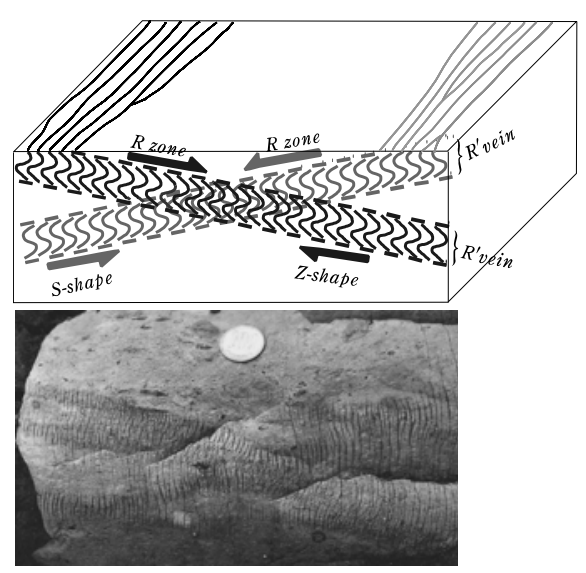

Fig. 6. Typical example of complex vein structures after oscillatory shaking by an earthquake. Two distinct vein arrays, one with $Z$-shaped veins and the other with S-shaped veins, were formed in Riedel shear zones (top to the right and top to the left, respectively). Sample from Shimatogura, Boso Peninsula. Coin is $22 \mathrm{~mm}$ in diameter.

In the case of oscillatory shearing, for example, during earthquake vibration, reciprocal shears may occur repeatedly, forming an upper liquefied part and a lower standing wave part, in between which the oscillatory shears occur. Then, bidirectional Riedel shears can form an $\mathrm{X}$-shape arrangement of vein structures (Fig. 6). One array has S-shaped veins, formed by top shear to the right, and the other Z-shaped veins, formed by top shear to the left (Fig. 6). We have observed various examples caused by such oscillatory shaking, and in most cases earthquake vibration of the topmost part of the sediment was the cause of the reciprocal shear underneath. However, the basic cause of the vein structure phenomenon is not necessarily earthquake vibration but is more likely dislocation by shear stress.

\section{Conclusions}

Vein structures have been 
described as a kind of seismite, but careful field observation of array height versus vein spacing and the results of a clay powder box shaking experiment, along with consideration of several possible factors, suggest that vein structures are not the direct product of earthquake mechanism similar to that by which ripple marks form. The main requirement is shear or oscillatory flow directly above the zone where vein structures form, and formation of a standing wave of short wavelength (on the order of millimeters to centimeters) in the zone where the vein structure forms.

\section{References}

Arthur, M. A., Carson, B., Von Huene, R., 1980. Initial tectonic deformation of hemipelagic sediment at the leading edge of the Japan convergent margin. In : Langseth, M., Okada, H. et al. (Eds.), Initial Report of DSDP 56/57, 569-613.

Bagnold, R.A., 1946. Motion of waves in shallow water, interaction between waves and sand bottom. Proceedings of Royal Society of London 187, A., 1-18.

Brothers, R. J., Kemp, A. E. S., Maltman, A. J., 1996. Mechanical development of vein structures due to the passage of earthquake waves through poorly-consolidated sediments. Tectonophysics 260, 227-244

Cowan, D. S., 1982. Origin of 'vein structure' in slope sediments on the inner slope of the Middle America Trench off Guatemala. In: Von Huene, R., Aubouin, J. et al. (Eds.), Initial Report of DSDP 57, 645-50.

Hanamura, Y., Ogawa, Y., 1993. Layer parallel faults, duplexes, imbricate thrusts, and vein structures of the Miura Group: Keys to understanding the Izu forearc sediment accretion to the Honshu forearc. The Island Arc 3, 126-141.

Helm, R., Vollbrecht, A., 1985. Brittle-ductile shear zones in slope sediments off Guatemala, Site 568 and 569, Deep Sea Drilling Project Leg 84. In von Huene, R., Aubouin, J., et al. (Eds.), Initial Report of DSDP, Washington (U.S. Govt. Printing Office) 84, 625-632.

shaking nor necessarily of oscillatory shaking, but are caused by shearing below a density flow. Vein spacing is not caused by push waves but by shear waves of very short wavelength induced by the density flow, and the spacing-grain size relationship can be explained by a

\section{Acknowledgments}

We thank Diaa Eldin Mohamed Kamel Hamed, who helped us with the experimental work in the early part of the study. The early draft was reviewed and revised by Alexander Maltman and Nicholas Hayman, to whom we are grateful, but we are responsible for any errors.

Inokuchi, M., 1975. Hydrology of drift and flow sands. Kokinshoin, Tokyo, 290pp.

Kemp, A.E.S., 1990. Fluid flow in "vein structures" in Peru forearc basins: Evidence from back-scattered electro microscope studies. In: Suess, E.,

von Huene, R., et al. (Eds.), Proceedings of ODP, Scientific Results 112, 33-41.

Kemp, A.E.S., Lindsley-Griffin, N., 1990. Variations in structural style within Peruvian forearc sediments. In: Suess, E., von Huene, R., et al., (Eds.), Proceedings of ODP, Scientific Results 112, 17-31.

Knipe, R.J., 1986. Microstructural evolution of vein arrays preserved in Deep Sea Drilling cores from the Japan Trench, Leg 57. Geological Society of America Memoir 166, 75-87.

Leggett, J. K., Lundberg, N., Bray, C. J., Cadet, J. P., Karig, D. E., Knipe, R. J., von Huene, R., 1987. Extensional tectonics in the Honshu forearc, Japan: integrated results of Deep Sea Drilling Project Legs 57, 87 , and reprocessed seismic reflection profiles. Geological Society of London, Special Publication 28, 593-609.

Lindsley-Griffin, N., Kemp, A., Swartz, J.F., 1990. Vein structures of the Peru margin, Leg 112. In: Suess, E., von Huene, R., et al., (Eds.), Proceedings of ODP, Scientific Results 112, 3-16.

Ogawa, Y., 1980. Beard-like veinlet structure as fracture cleavage in the Neogene siltstone in the Miura and 
Boso Peninsulas, central Japan. Science Report, Department of Geology, Kyushu University, Japan 13, 321-327.

Ogawa, Y., Miyata, Y., 1985. Vein structure and its deformation history in the sedimentary rocks of the Middle America Trench slope the Izu-Bonin forearc, ODP Leg 126. In: Taylor, B., Fujioka, K. et al. (Eds.), Proceedings of ODP, Scientific Results 126, 195-207.

Ohsumi, T., Nagayama, T., Makinou, T., 2006. Study of detection system for off Guatemala, Deep Sea Drilling Project Leg 84. In von Huene, R., Aubouin, J., (Eds.), Initial Report of DSDP, Washington (U.S. Govt. Printing Office) 84, 811-529.

Ogawa, Y., Ashi, J., Fukioka, K., 1992. Vein structure and their tectonic implication for the development of debris flows, earthquakes and noise by vibration sensor. Journal of Sabo Society 59, 38-43.

Yalin, M. S., 1972. Mechanics of sediment transport. Pergamon Press, Oxford, U.K., 290pp.

(The End) 